\title{
Spray deposition of sulfonated cellulose nanofibers as electrolyte membranes in fuel cells
}

\author{
Thomas Bayer • Benjamin Vaughan Cunning • Břetislav Šmíd • \\ Roman Selyanchyn $\cdot$ Shigenori Fujikawa $\cdot$ Kazunari Sasaki $\cdot$ Stephen Matthew Lyth
}

Received: 27 May 2020/ Accepted: 16 November 2020/Published online: 3 January 2021

(C) The Author(s) 2021

\begin{abstract}
Nanocellulose is a promising new membrane material for fuel cells, with much lower cost and environmental impact compared with Nafion or Aquivion. It is mechanically strong, is an excellent hydrogen barrier and has reasonable proton conductivity.Here, sulfonation of cellulose nanofibers is performed to enhance the conductivity (up to $2 \times 10^{-3} \mathrm{~S} \mathrm{~cm}^{-1}$ ) without compromising the
\end{abstract}

Electronic supplementary material The online version of this article (https://doi.org/10.1007/s10570-020-03593-w) contains supplementary material, which is available to authorized users.

T. Bayer · B. V. Cunning · B. Šmíd .

R. Selyanchyn - S. Fujikawa $\cdot$ K. Sasaki - S. M. Lyth International Institute for Carbon-Neutral Energy

Research (WPI-I2CNER), Kyushu University, 744

Motooka, Nishi-ku, Fukuoka 819-0395, Japan

T. Bayer $(\bowtie) \cdot$ K. Sasaki

Next-Generation Fuel Cell Research Center (NEXT-FC),

Kyushu University, 744 Motooka, Nishi-ku,

Fukuoka 819-0395, Japan

e-mail: bayerthomas@gmx.net

B. V. Cunning

Center for Multidimensional Carbon Materials (CMCM), Institute for Basic Science (IBS), Ulsan 44919, Republic of Korea

B. Šmíd

Faculty of Mathematics and Physics, Department of Surface and Plasma Science, Charles University, V

Holešovičkách 2, 18000 Prague 8, Czech Republic membrane integrity, and fuel cells are fabricated with $30 \mu \mathrm{m}$-thick "paper" membranes. The hydrogen crossover current is two orders of magnitude lower than for Nafion fuel cells with equivalent thickness, but the power density is rather low.Spray-coating is used to deposit $8 \mu \mathrm{m}$-thick membranes directly onto the electrocatalyst layer, in a process analogous to $3 \mathrm{D}$ printing or additive manufacturing. The resulting paper fuel cell has high current density $(>0.8 \mathrm{~A}$ $\left.\mathrm{cm}^{-2}\right)$ and power density $\left(156 \mathrm{~mW} \mathrm{~cm}^{-2}\right)$ under standard measurement conditions $\left(\mathrm{H}_{2} /\right.$ air; $80^{\circ} \mathrm{C} ; 95 \%$ $\mathrm{RH} ; 0.1 \mathrm{MPa}$ ), attributed to decreased membrane

\section{K. Sasaki}

International Research Center for Hydrogen Energy, Kyushu University, 744 Motooka, Nishi-ku, Fukuoka 819-0395, Japan

\section{K. Sasaki}

Department of Mechanical Engineering, Kyushu University, 744 Motooka, Nishi-ku, Fukuoka 819-0395, Japan

S. M. Lyth

Kyushu University Platform of Inter/Transdisciplinary

Energy Research (Q-PIT), 744 Motooka, Nishi-ku,

Fukuoka 819-0395, Japan

S. M. Lyth ( $₫)$

Energy2050, Department of Mechanical Engineering,

University of Sheffield, Sheffield S10 2TN, UK

e-mail: 1yth@i2cner.kyushu-u.ac.jp 
resistance. The cost of the spray-painted cellulose membranes is calculated to be $\sim 50 \$ \mathrm{~m}^{-2}$, which is much lower than that of Nafion, even without taking into consideration economies of scale. This new concept in electrochemical energy conversion paves the way for the mass production of affordable, recyclable fuel cells.

\section{Graphic abstract}

(Peighambardoust et al. 2010; Yee et al. 2012). This is typically Nafion, which is a sulfonated fluoropolymer and a registered trademark of DuPont. The commercial price of Nafion membranes currently ranges from e.g. 700-1400 $\$ \mathrm{~m}^{-2}$, depending on the supplier and scale of purchase (Peighambardoust et al. 2010; Yee et al. 2012). Due to this high price, PEFC membranes are estimated to account for $28 \%$ of the total cost of a PEFC stack (at a production scale of
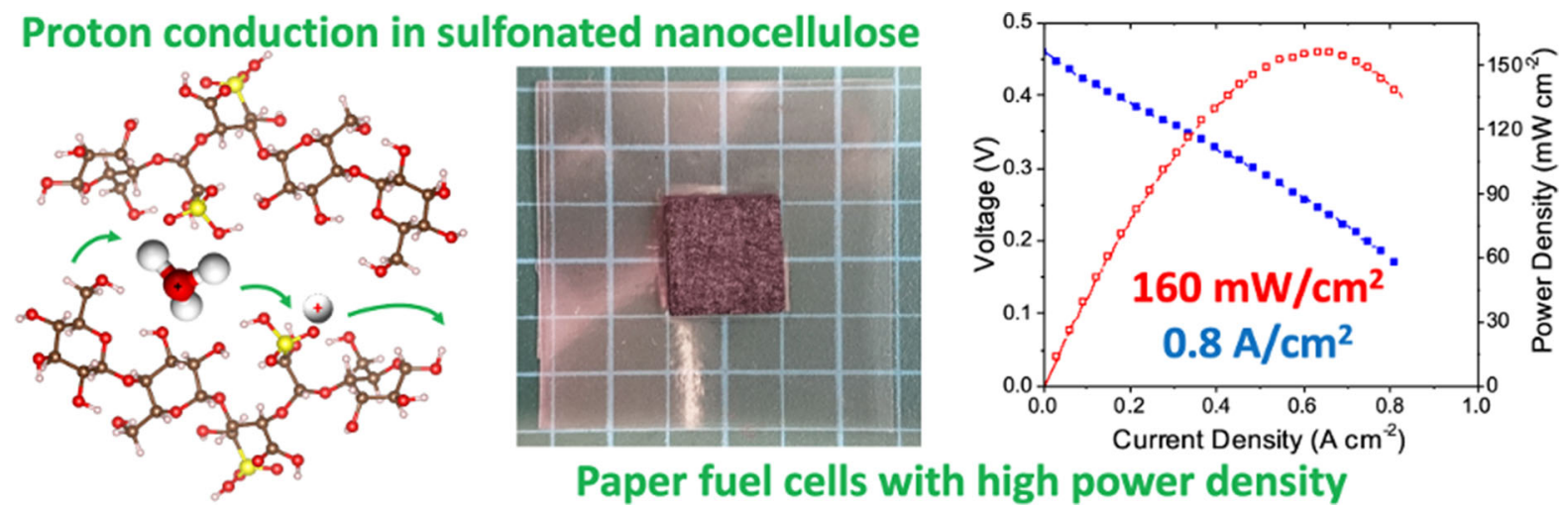

Paper fuel cells with high power density

Keywords Nanocellulose $\cdot$ Fuel cell · PEFC . Hydrogen energy · Proton conduction · Cellulose nanofibers

\section{Introduction}

Polymer electrolyte fuel cells (PEFCs) are one technology helping us to move away from fossil fuels and towards a hydrogen economy, powered by renewable energy. PEFCs fuelled by hydrogen have already been commercialized in stationary residential applications and as fuel cell vehicles (FCVs) in Japan (Sasaki et al. 2016). Other international vehicle manufacturers are now following suit, with plans to launch FCVs commercially in the near future. However, PEFCs currently are far more expensive than conventional combustion engines or batteries, partly due to the high cost of the fuel cell stack (as well as the hydrogen storage system) (Sun et al. 2010; Eberle et al. 2012). This high cost hampers their widespread distribution, thus limiting their potential impact on $\mathrm{CO}_{2}$ and PM2.5 emissions.

One of the major factors contributing to the high cost of PEFCs is the ionomer membrane
1000 systems per year) (Marcinkoski et al. 2015). Clearly, substituting Nafion with a cheaper ionomer material could have a major impact on system cost, with a corresponding increase in market penetration. The United States Department of Energy (US DOE) has specific targets for PEFC membranes for FCVs including: a cost of $<20 \$ \mathrm{~m}^{-2}$; a hydrogen crossover current of $<2 \mathrm{~mA} \mathrm{~cm}^{-2}$; an operation temperature $>120^{\circ} \mathrm{C}$; and a durability of 20,000 cycles, by 2020 (U.S. Department of Energy 2016). To satisfy all of these requirements will be extremely challenging. However, if selected targets (e.g. cost and hydrogen crossover) can be significantly exceeded, the other targets may be relaxed. In addition, stationary and portable fuel cell systems have less stringent targets, with cost playing a more heavily weighted role. Therefore, there is a potential gap-in-the market for low cost ionomer membranes with e.g. superior hydrogen barrier properties.

Cellulose is a biopolymer produced at great bulk in nature in the cell walls of plants and trees. As such, this polymer is not a petrochemical and is not synthesized from oil. It is processed at a scale of billions of tonnes per year as biofuel, food, cardboard, and paper. More 
than 400 million tonnes of paper and cardboard alone are produced annually (RISI 2015). There is a huge recycling industry for paper and cardboard, and therefore cellulose can be easily obtained from renewable sources. Recently, nanocellulose has emerged as a new variant on traditional cellulosic materials (Dufresne 2013; Kim et al. 2015). Nanocellulose is obtained by breaking down micron-scale cellulose fibers by mechanical, sonic, biological, or chemical treatments. The resulting cellulose nanofibers (CNFs) or cellulose nanocrystals (CNCs) can be readily dispersed in water to form gels or pastes. These dispersions can be filtered or printed to form strong, transparent nanocellulose membranes with temperature stability up to $150{ }^{\circ} \mathrm{C}$ (Henriksson et al. 2008; Nogi et al. 2009; Nogi et al. 2013). Applications of nanocellulose have so far included food packaging, textiles, lightweight polymer composites, intelligent inks, biomedical uses, adhesives, coatings, and even flexible organic solar cells (Dufresne et al. 2013; Lin and Dufresne 2014; Lee et al. 2014; Kim et al. 2015).

Nanocellulose is also a candidate material for use as an ionomer in P\EFC membranes. It has been reported to have excellent thermal stability of $>250{ }^{\circ} \mathrm{C}$ (Börjesson et al. 2018), well above the operating temperature of PEFCs and comparable to that of Nafion $\left(280{ }^{\circ} \mathrm{C}\right)$ (Samms et al. 1996). It has been used as an additive in conventional ionomers such as Nafion. For example, Gadim et al. (2016) impregnated a bacterial nanocellulose membrane with Nafion and obtained a PEFC power density of $16 \mathrm{~mW} \mathrm{~cm}^{-2}$ at room temperature. Jiang et al. (2015) prepared a bacterial nanocellulose / Nafion composite (1:7 wt \%) by solvent casting, obtaining a PEFC power density of $106 \mathrm{~mW} \mathrm{~cm}^{-2}$ at room temperature. In previous work, we showed for the first time that pure nanocellulose paper is a proton conductor and can function as an ionomer membrane. Membranes around $30 \mu \mathrm{m}$ in thickness were fabricated from CNFs by vacuum filtration. They were weak proton conductors, but with impressive strength, and hydrogen permeability three orders of magnitude lower than Nafion (Bayer et al. 2016a). The proton conductivity was much higher in membranes fabricated from $\mathrm{CNCs}$, due to the presence of sulfonic acid groups. However, CNC membranes were mechanically weak and unstable in water, and the maximum PEFC power density obtained was just $17 \mathrm{~mW} \mathrm{~cm}^{-2}$. Whilst this work was an important proof-of-concept, the performance was clearly far from sufficient for practical fuel cell applications. Increasing the proton conductivity of nanocellulose without compromising the mechanical stability and water tolerance, as well as reducing the membrane thickness is imperative.

Here, we synthesize sulfonated cellulose nanofibers (S-CNFs) to improve the ionic conductivity, whilst hopefully maintaining high mechanical strength and good water tolerance. Instead of vacuum filtration, which usually yields rather thick free-standing membranes (e.g. several tens of microns), spray-deposition is utilized here to directly coat thin S-CNF membranes onto an electrode-supported electrocatalyst layer, followed by spray-deposition of a top electrode electrocatalyst layer, in a process akin to additive manufacturing or 3D printing. The reduced thickness of the membrane results in significantly reduced membrane resistance, leading to enhanced PEFC performance. Whilst difficult to directly compete with established (but more expensive) ionomers such as Nafion, our S-CNF PEFCs already have power density comparable to other "low cost" technologies such as direct methanol fuel cells (DMFCs), or PEFCs using non-platinum group metal (non-PGM) catalysts. As such, these innovations bring commercialization of cheap, Nafion-free PEFCs a step closer.

\section{Methods}

Cellulose nanofiber (CNF) slurry (extracted from wood pulp via ultra-fine friction grinding, $3.0 \mathrm{wt} \%$ solids) was purchased from the University of Maine. A schematic of the nanocellulose sulfonation procedure is shown in Fig. 1a (Rajalaxmi et al. 2010). $100 \mathrm{~g}$ of CNF slurry was dispersed into $100 \mathrm{ml}$ distilled water. $0.6 \mathrm{~g}$ of sodium periodate (Sigma Aldrich, Japan) was mixed into the dispersion and the flask was covered with aluminium foil to protect it from light. The dispersion was then stirred for 72 hours at room temperature. The product (2,3-dialdehyde nanocellulose) was then washed with water 5 times by centrifugation (High-speed Micro Centrifuge CF16RN, Hitachi, Japan, $5500 \times g, 1$ h), discarding the supernatant after each run. The 2,3-dialdehyde nanocellulose was then dispersed into $50 \mathrm{ml}$ distilled water and reacted with $3 \mathrm{~g}$ sodium bisulfite (Sigma Aldrich, Japan). This dispersion was stirred for three days and the resulting product was washed five times 
a)
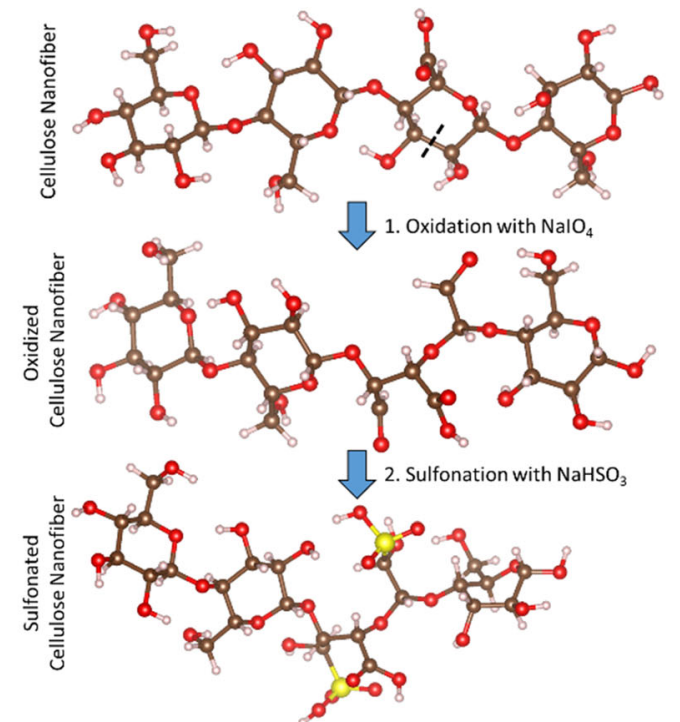

CNF Paper

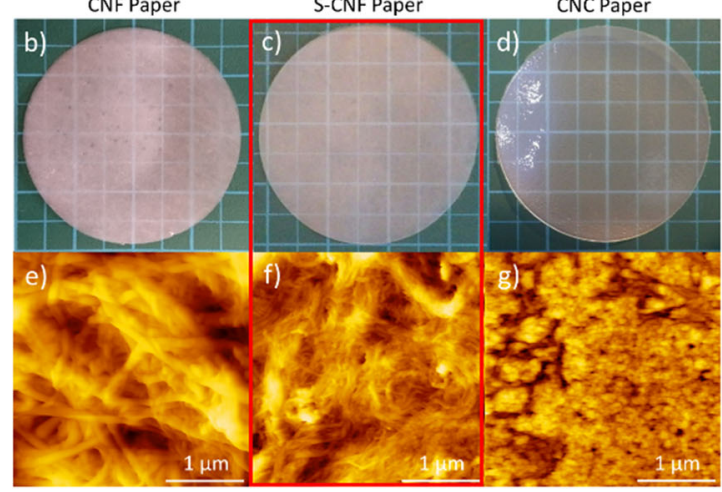

Fig. 1 a Schematic showing the chemical structure of cellulose, and the procedure for sulfonation (created using VESTA). (Momma and Izumi 2011). b-d Photographs and e-g AFM images of nanocellulose paper derived from CNF, S-CNF, and CNC respectively

at higher centrifugation speed $(14,000 \times g, 1 \mathrm{~h})$. Finally, ion exchange was performed by adding $1 \mathrm{~mL}$ concentrated hydrochloric acid to the dispersion, followed by centrifugation washing $(14,000 \times g$, $1 \mathrm{~h})$. This ion exchange procedure was repeated twice to ensure the reaction went to completion.

The dispersions of sulfonated cellulose nanofibers (S-CNFs) were filtered and dried (hydrophilic PTFE Millipore filters, with a pore size of $0.1 \mu \mathrm{m}$ ). The resultant S-CNF membranes were hot-pressed between Teflon sheets for $20 \mathrm{~min}$ at $110^{\circ} \mathrm{C}$ and 1.1 $\mathrm{MPa}$, before being peeled from the filter. A schematic of this preparation process is in the supplementary information of our previous publication (Bayer et al. 2016a).
Fuel cell related properties of our nanocellulose membranes e.g. tensile strength, gas barrier and proton conductivity were compared with Nafion ${ }^{\circledR}$ PFSA NR212 (Sigma Aldrich, Japan, $50.8 \mu \mathrm{m}$ thickness), hereafter referred to as "Nafion".

The morphology of the nanocellulose was observed using atomic force microscopy (AFM, Seiko Instruments, Japan, SPA300HV; SPI $3800 \mathrm{~N}$ probe station; $\mathrm{SN}-\mathrm{AF} 01$ cantilever), after being dropping from dispersion onto silicon substrates. The average roughness was calculated from a total of 20 horizontal and vertical line profiles. X-ray photoelectron spectroscopy (XPS) was used to determine the chemical composition (PHI 5000 Versa Probe II), and the data was charge-corrected. Fourier transform infrared spectroscopy (FT-IR) was collected in attenuated total reflection (ATR) mode using an infrared imaging microscope (Nicolet iN10 MX, Thermo Fisher Scientific, Japan).

The ion exchange capacity (IEC) was obtained by immersing nanocellulose membranes in $1 \mathrm{M} \mathrm{NaCl}$ solution for $72 \mathrm{~h}$, followed by titration to neutral $\mathrm{pH}$ with $0.001 \mathrm{M} \mathrm{NaOH}$ solution.

Tensile strength, elongation until rupture, and elastic modulus were measured at ambient temperature and relative humidity $(\sim 65 \%)$. Samples were cut into dumbbell shaped specimens (total length $35 \mathrm{~mm}$, $2 \mathrm{~mm}$ sampling width) using a bespoke punch. A hydraulic testing machine with $5 \mathrm{~N}$ force gauge (FGOC-TV, NIDEC-SHIMPO, Japan) was used to apply tensile load, until rupture, with an elongation speed of $10 \mathrm{~mm}$ per minute. The tensile stress was calculated from the applied force and the cross-sectional area of the individual specimen (thickness $\mathrm{x}$ width). In five samples each of CNF paper and Nafion, and three samples of S-CNF were used for tensile strength testing.

Water uptake and swelling of the membranes were investigated by immersion in deionized water. Samples $(10 \times 10 \mathrm{~mm}$ square $)$ were first vacuum dried at $80{ }^{\circ} \mathrm{C}$ for two hours. The mass and thickness were measured using an analytical balance (Mettler Toledo, USA, $\pm 0.1 \mathrm{mg}$ ) and a micrometer (Mitutoyo, Japan $\pm 1 \mu \mathrm{m})$, respectively. The specimens were then submerged in a water bath at ambient temperature, for 60 minutes. The samples were then removed, and any excess surface water was carefully removed using tissue paper. Finally, the mass and thickness were measured again. 
Water uptake was calculated as an average from 5 separate measurements, where $\mathrm{m}_{\text {wet }}$ and $\mathrm{m}_{\mathrm{dry}}$ are the wet and dry masses, respectively:

Water Uptake $(\%)=\frac{m_{w e t}-m_{d r y}}{m_{d r y}} \cdot 100 \%$

Swelling was calculated as follows, where $t_{\text {wet }}$ is thickness measured when saturated with water, and $\mathrm{t}_{\mathrm{dry}}$ is the initial thickness.

Swelling $(\%)=\frac{\mathbf{t}_{w e t}-t_{d r y}}{t_{d r y}} \cdot 100 \%$

The chemical stability of nanocellulose membranes and Nafion were investigated by using Fenton's test (Fenton 1894). The samples were dried in vacuum at $80{ }^{\circ} \mathrm{C}$ for two hours, and then their dry weight was measured. The samples were then immersed into Fenton's reagent $\left(200 \mathrm{ml} \mathrm{H}_{2} \mathrm{O}_{2}, 20 \mathrm{ppm} \mathrm{Fe}^{2+}\right)$ at $80{ }^{\circ} \mathrm{C}$ for one hour. Finally, the samples were vacuumdried again and their weight loss was determined.

Measurement of gas permeance was performed by masking the membrane area with Kapton ${ }^{\circledR}$ and aluminum tape to obtain the desired area of interest $\left(S=0.2-1.3 \mathrm{~cm}^{2}\right)$. A porous polycarbonate support filter (Isopore ${ }^{\mathrm{TM}}$, RTTP, $1.2 \mu \mathrm{m}$ pore size) was used to prevent membrane deformation during measurements. A gas barrier testing system (GTR-11A/31A, GTR Tec Corp., Japan) was used to measure the dry hydrogen permeability between room temperature (ca. $25^{\circ} \mathrm{C}$ ) and $80{ }^{\circ} \mathrm{C}$. Gas permeation was induced by applying pressure at the feed side, and a vacuum on the permeate side, with a total transmembrane pressure differential of $200 \mathrm{kPa}$ (Bayer et al. 2016b). The sample collection time $(t)$ after vacuuming the permeate side of the membrane was 30 minutes. The collected gas was transferred to a gas chromatograph combined with a thermal conductivity detector (G3700T, Yanaco, Japan) and the volume ( $V)$ was measured. Gas permeability is defined as $P=V \times l / S \times t \times \Delta p$; with volume of the permeated gas at standard temperature and pressure $(\mathrm{V})$, membrane thickness (l), membrane area (S), time of gas sample collection (t) and transmembrane pressure $(\Delta p)$.

The membrane conductivity was investigated at different temperature and relative humidity using a membrane testing device (MTS-740, Scribner Associates, USA) in tandem with an impedance analyzer (Solartron SI1260) (Cooper 2019). An S-CNF membrane with a thickness of $23 \mu \mathrm{m}$ was measured at an $\mathrm{AC}$ amplitude of $10 \mathrm{mV}$ in a frequency range from 30 to $10 \mathrm{~Hz}$, between 30 and $120{ }^{\circ} \mathrm{C}$ at $100 \%$ RH. At $>100{ }^{\circ} \mathrm{C}$ the measurement chamber was pressurized. An equivalent circuit was fitted using ZPlot (Scribner), and the resistance (R) determined from the high frequency intercept. The conductivity $(\sigma)$ was calculated from Eq. 3, where L is the membrane thickness in $\mathrm{cm}, \mathrm{R}$ is the membrane resistance in, and $\mathrm{A}$ is the cross-sectional area $\left(0.5 \mathrm{~cm}^{2}\right)$ (Bayer et al. 2014).

$\sigma=\frac{L}{R \cdot A}$

S-CNF paper with a thickness of $28 \mu \mathrm{m}$ was used to fabricate a membrane electrode assembly (MEA). The catalyst ink was a mixture of Pt/C (Tanaka Kikinzoku Kogyo K.K., Japan, 46.2 wt\% Pt) and 5 wt\% Nafion (Sigma Aldrich, Japan), ethanol (Sigma Aldrich, Japan), and deionized water. Whilst nanocellulose will be explored in the future as an electrode ionomer in its own right, at this stage it is important to investigate these new membranes using state-of-theart electrocatalyst layers. The catalyst ink was stirred overnight, and sonicated for $30 \mathrm{~min}$ before use (SMT Ultra Sonic Homogenizer UH-600). Catalyst ink was sprayed onto the membranes (Nordson K.K. Spraying Device, C-3J) with an electrode size of $0.5 \mathrm{~cm}^{2}$, and a loading of $0.3 \mathrm{mg}_{\mathrm{Pt}} \mathrm{cm}^{-2}$ at both the anodeand cathode. The MEA was then sandwiched between hydrophobic carbon paper gas diffusion layers (GDLs, EC-TP1-060T) at $0.2 \mathrm{kN}$ for $190 \mathrm{~s}$ at $132{ }^{\circ} \mathrm{C}$.

In order to increase the performance, an electrodesupported MEA was fabricated in the same process as reported by Breitwieser et al. previously (Klingele et al. 2015; Breitwieser et al. 2017). First, catalyst ink was sprayed onto two pieces of carbon paper $(\mathrm{H} 23 \mathrm{C} 8$, Freudenberg, Germany, $1 \times 1 \mathrm{~cm}$ ) with a total loading of $0.3 \mathrm{mg}_{\mathrm{Pt}} \mathrm{cm}^{-2}$. This carbon paper was then hotpressed for 3 minutes at $132{ }^{\circ} \mathrm{C}$ and $0.3 \mathrm{kN}$ (Digital Press CZPT-10, Sinto, Japan). Then, S-CNF/water/ ethanol dispersion (1:18.5:43.8 mass ratio) was sprayed onto the electrocatalyst layers, with a thickness of $\sim 4$ microns (measured by micrometer). Finally, these sprayed components were assembled into a MEA with a $0.5 \mathrm{~cm}^{2}$ active area, by using a PTFE sub-gasket.

The MEAs were installed in a NEDO single cell holder $\left(1 \mathrm{~cm}^{2}\right.$ flow field), and their performance was 
measured in a fuel cell test rig (AutoPem-CVZ01, Toyo Corporation, Japan). The cells were preconditioned for two hours at $80{ }^{\circ} \mathrm{C}$ and a nitrogen gas flow of $100 \mathrm{ml} \mathrm{min}^{-1}$ (95\% RH). The gas flow was then swapped to hydrogen and air $\left(100 \mathrm{ml} \mathrm{min}^{-1}, 95 \%\right.$ $\mathrm{RH}$ ), and the performance was measured after waiting for ten minutes. Polarization curves, power density plots, and durability were investigated by potentiostat (VersaSTAT 4, Amtek, USA and Fuel Cell Test System 890e, Scribner Associates, USA) (Bayer et al. 2014; Bayer et al. 2016a).

The in-situ hydrogen crossover was determined after the IV-curve measurement by linear sweep voltammetry (LSV). Hydrogen and nitrogen were fed to the anode and cathode at a constant flow rate of $100 \mathrm{ml} \mathrm{min}{ }^{-1}$. The potential of the cell was swept in $20 \mathrm{mV}$ steps from the rest potential to $0.6 \mathrm{~V}$ using a Solartron SI1280 potentiometer (Solartron Analytical, England). The hydrogen crossover current density was evaluated at $300 \mathrm{mV}$ (Inaba et al. 2006).

\section{Results and discussion}

Appearance and morphology

Conventional nanocellulose paper is generally optically opaque (Sethi et al. 2018; Ismail et al. 2019), but with increasing crystallinity its transparency increases, due to the smaller fibre size and reduced scattering of light. Figure $1 \mathrm{~b}-\mathrm{d}$ shows photographs of paper fabricated by vacuum filtration of cellulose nanofibers (CNF), sulfonated cellulose nanofibers (S$\mathrm{CNF}$ ), and cellulose nanocrystals (CNC), respectively. Atomic force microscopy (AFM) of the surfaces (Fig. 1e-g) clearly reveals the fibrous nature of CNFs, and the crystal-like nature of CNCs with much lower aspect ratio. This difference in structure is behind the large difference in mechanical properties and water tolerance, as discussed later (Bayer et al. 2016a). After sulfonation of CNFs, the fibrous structure and large aspect ratio is retained in S-CNFs, whilst the fibril diameter is significantly reduced to around $50 \mathrm{~nm}$. The retention of the fibrous structure even after sulfonation is expected to contribute to mechanical stability of $\mathrm{S}-\mathrm{CNF}$ membranes, as compared to CNCs.
Chemical composition

XPS was used for elemental analysis (Fig. 2a, b). Figure $2 \mathrm{a}$ shows the wide-scan spectra for CNF, $\mathrm{S}-\mathrm{CNF}$ and $\mathrm{CNC}$, which all have two major peaks (the $\mathrm{C} 1 \mathrm{~s}$ excitation at $285 \mathrm{eV}$ and $\mathrm{O} 1 \mathrm{~s}$ excitation at $532 \mathrm{eV}$ ). For S-CNF, a small but clear peak appears at $169 \mathrm{eV}$ after sulfonation of CNF, corresponding to the S 2p region (Rodella et al. 2015). This is evidence of the successful introduction of sulphur-containing functional groups at a concentration of $\sim 0.2$ at $\%$. $\mathrm{CNC}$ has a larger peak at this energy, corresponding with the much harsher sulfonation process used to break apart the fibres into crystals. The CNF and S-CNF samples also display a small peak at $689 \mathrm{eV}$ corresponding to fluorine contamination (F $1 \mathrm{~s}$ ) from the Teflon sheets used in hot-pressing.

The elemental composition of CNF according to XPS is $62.0 \% \mathrm{C}, 36.4 \% \mathrm{O}$, and $1.6 \% \mathrm{~F}$. The composition of $\mathrm{S}-\mathrm{CNF}$ is $30.4 \% \mathrm{C}, 66.4 \% \mathrm{O}, 0.2 \%$ $\mathrm{S}$, and $3.0 \% \mathrm{~F}$. The composition of $\mathrm{CNC}$ is $54.5 \% \mathrm{C}$, $41.0 \% \mathrm{O}, 0.8 \% \mathrm{~S}$, and $0.8 \% \mathrm{Na}$. For further information, the $\mathrm{C} 1 \mathrm{~s}$ spectrum is included in the supplementary information (Figure S1) and its peak deconvolution is discussed.

Because XPS is not sufficiently sensitive to confirm successful sulfonation at concentrations below $\sim 1$ at\%, FTIR was also performed (Fig. 2c). The peak appearing at $\sim 890 \mathrm{~cm}^{-1}$ for both S-CNF and CNC papers corresponds to stretching vibrations of $\mathrm{S}-\mathrm{O}$ bonds (Gaspar et al. 2014), providing further confirmation of the successful sulfonation of CNF. Unfortunately, peaks corresponding to asymmetric and symmetric stretching vibrations of $\mathrm{S}=\mathrm{O}$ bonds (at $\sim 1079$ and $\sim 1229 \mathrm{~cm}^{-1}$, respectively) (Bayer et al. 2016a), are not observed. This may be due to the low concentration of sulfur $(<1$ at $\%)$, or masking by other larger peaks. Despite this, XPS and FTIR data essentially confirm the success of the sulfonation reaction.

\section{Tensile strength}

The mechanical properties of ionomer membranes are important when considering integration into MEAs, especially in the case of very thin membranes, which can tear or perforate more easily. The tensile strength of Nafion is $30.7 \pm 0.4 \mathrm{MPa}$ (Bayer et al. 2014). In 

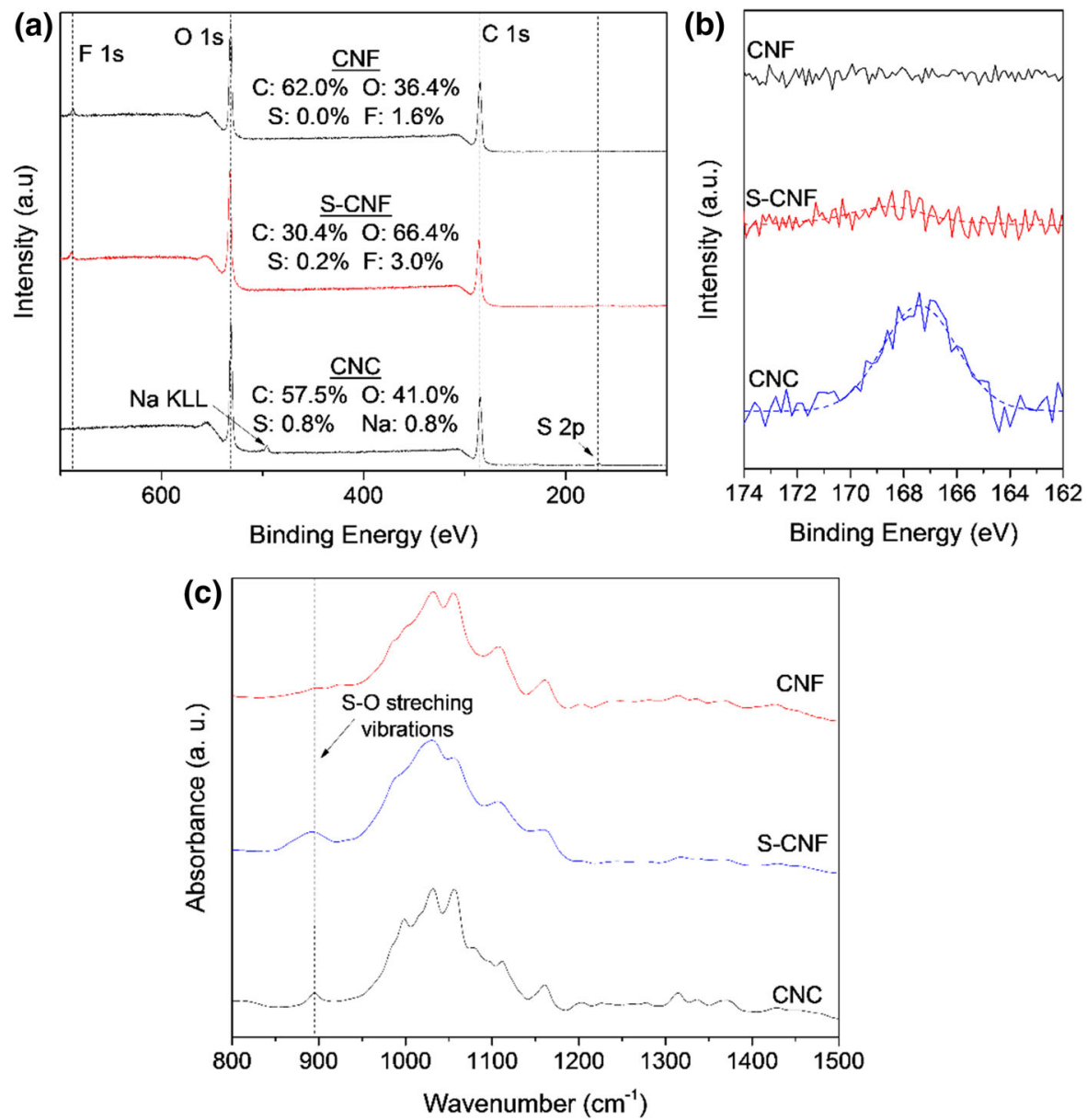

Fig. 2 XPS spectra of cellulose nanofibers (CNF), sulfonated cellulose nanofibers (S-CNF), and cellulose nanocrystals (CNC): a wide scan spectra; and b $\mathrm{S} 2 \mathrm{p}$ region. $\mathbf{c}$ FTIR spectra

previous work, we measured the tensile strength of CNF paper to be an impressive $122.8 \pm 4.8 \mathrm{MPa}$. This was attributed to the dense hydrogen bonding network between individual nanofibers (Henriksson et al. 2008; Dufresne 2013), and the high tensile strength of the individual fibres (7.6 GPa) ) (Börjesson and Westman 2015). Paper fabricated from CNCs was too brittle to measure due to the small aspect ratio, making it unsuitable for use in MEAs. Here, we measured the average tensile strength of S-CNF paper to be $42.2 \pm 4.2 \mathrm{MPa}$ (Figure $\mathrm{S} 2$ ). This is much lower than CNF but is still significantly higher than Nafion, despite the large error (which arises due to a smaller sample size). The elastic modulus of S-CNF paper (i.e. the gradient of the stress-strain curve in the elastic region) is $1.09 \pm 0.38 \mathrm{GPa}$, compared with is $5.63 \pm 0.57 \mathrm{GPa}$ for $\mathrm{CNF}$ and $94.9 \pm 8.5 \mathrm{MPa}$ for
Nafion. The reduced elastic modulus of S-CNF compared to CNF is most likely a result of the decreased fiber dimensions and possibly reduced hydrogen-bond interactions. The error is relatively large for S-CNF, reflecting significant variation in the elastic modulus. This may reflect local inhomogeneities in the membranes. The results of tensile strength tests indicate that S-CNF paper is clearly strong enough for integration into MEAs.

Water uptake and swelling

The water uptake properties of polymer electrolyte membranes (PEMs) are important because proton conduction generally occurs via water-mediated Grotthuss and/or vehicular mechanisms. Some level of water uptake is therefore required, but too much can 

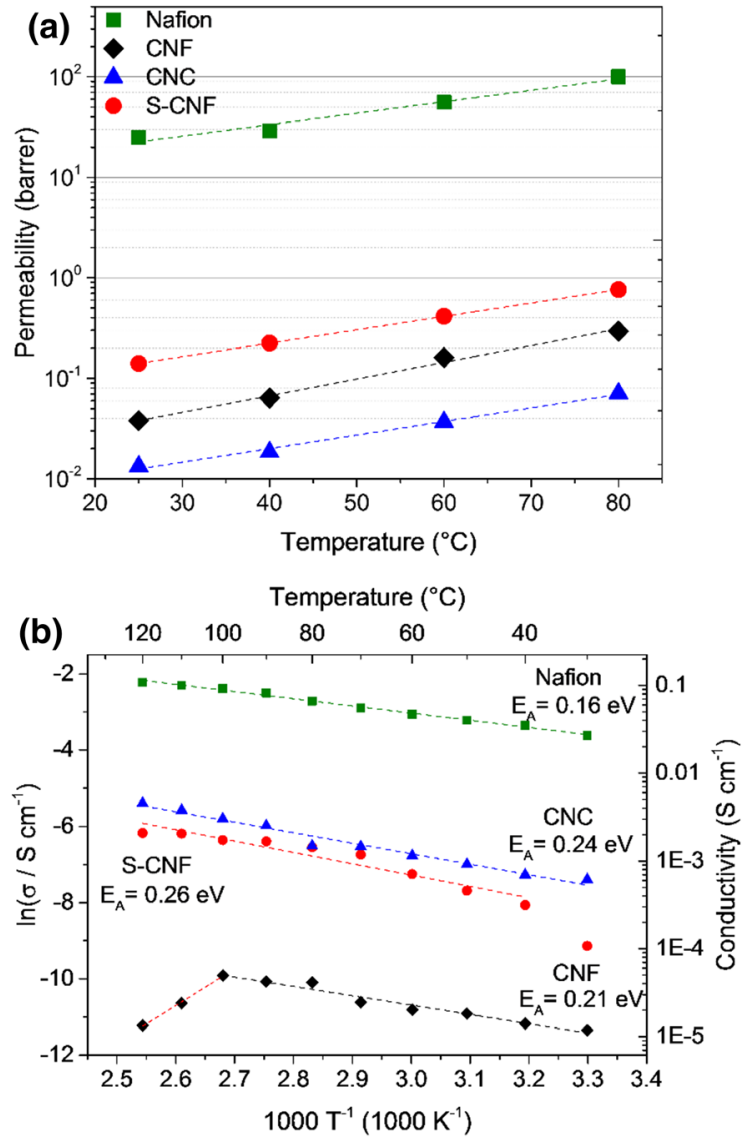

Fig. 3 a Hydrogen permeability through nanocellulose membranes and Nafion. b Arrhenius plot with activation energies and through-plane proton conductivity of nanocellulose and Nafion membranes

lead to swelling and loss of mechanical strength. For example, we previously showed that $\mathrm{CNC}$ membranes swell strongly, forming an extremely fragile hydrogeltype structure, and making them unsuitable for PEFCs (Bayer et al. 2016a). Here, we measured the water uptake of S-CNF to be $26 \pm 3 \%$, and the swelling to be $14 \pm 5 \%$. These values are quite close to those measured for Nafion $(26 \pm 2 \%$ and $16 \pm 2 \%$ (Bayer et al. 2014)), respectively). These results indicate that $\mathrm{S}-\mathrm{CNF}$ membranes are well-suited for use in PEFCs.

\section{Chemical stability}

The oxidative stability of the nanocellulose paper was investigated using Fenton's test for a duration of one hour. The CNF paper had high oxidative stability, retaining $97.5 \%$ of its mass during the test (comparable to Nafion at 99.3\%). The CNC membrane completely dissolved due to high hydrophilicity and the low aspect ratio. S-CNF retained $64.3 \%$ of its mass, suggesting that it is reasonably stable. The slightly reduced stability compared with CNF is likely related to the smaller nanofiber diameter, as well as opening of the polysaccharide rings during synthesis of $\mathrm{CNC}$, compromising the chemical stability.

\section{Gas barrier properties}

Low hydrogen permeability is a crucial property for PEFC membranes. If hydrogen crossover occurs between the anode and cathode, the hydrogen reacts directly with oxygen reducing the efficiency of the cell and causing hotspots which can dangerously degrade the cell. We previously showed that nanocellulose membranes (both $\mathrm{CNF}$ and $\mathrm{CNC}$ ) are excellent hydrogen barriers. Here we can observe that S-CNF has slightly increased hydrogen permeability compared with CNF (Fig. 3a). This is possibly due to increased gas solubility in the presence of sulfonic acid groups (Chen and Martin 1994). Meanwhile, $\mathrm{CNC}$ has lower permeability despite the presence of sulfonic acid groups, but this could be due to the close packing of CNC crystals, as observed in the AFM images. All of the nanocellulose papers measured here have hydrogen permeability which is several orders of magnitude lower than that of Nafion, making them highly suited to PEFC applications.

Ion exchange capacity (IEC) and proton conductivity

The ion exchange capacity (determined by titration) was $0.900 \mathrm{mmol} \mathrm{g}^{-1}$ for S-CNF, compared with $0.016 \mathrm{mmol} \mathrm{g}^{-1}$ for CNF. This significant, six-fold increase is further evidence of the success of the sulfonation reaction. This value is also comparable to the IEC of Nafion (i.e. $0.92 \mathrm{mmol} \mathrm{g}^{-1}$ ). This suggests that there is a similar density of proton-conducting sites / charge carriers in both Nafion and S-CNF. The through-plane proton conductivity of S-CNF paper at $120{ }^{\circ} \mathrm{C}$ is $2 \times 10^{-3} \mathrm{~S} \mathrm{~cm}^{-1}$ (Fig. 3b). This is two orders of magnitude higher than the un-sulfonated CNF paper, showing that chemical functionalization had the desired effect of significantly enhancing the proton conductivity. However, the conductivity is still two orders of magnitude lower than Nafion $(\sim 0.1 \mathrm{~S}$ 
(a)

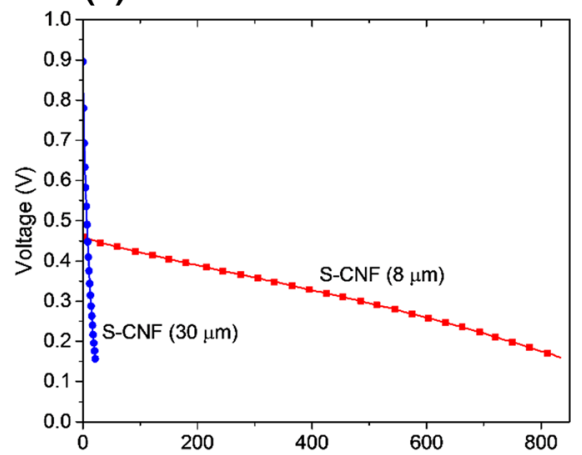

(C) Current Density $\left(\mathrm{A} \mathrm{cm}^{-2}\right)$

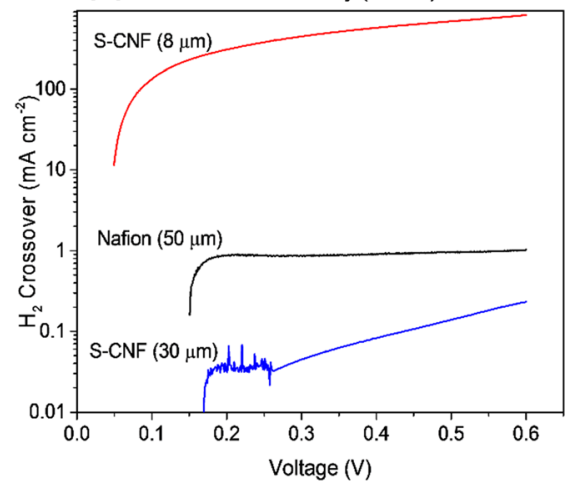

Fig. 4 IV and power density curves of a fuel cells with: a $30 \mu \mathrm{m}$-thick; and b $8 \mu \mathrm{m}$-thick sulfonated nanocellulose (S$\mathrm{CNF}$ ) membranes. c Comparison of hydrogen crossover current

$\mathrm{cm}^{-1}$ at $120^{\circ} \mathrm{C}$ ). Since the IEC of S-CNF is similar to that of Nafion, the lower conductivity must be attributed to the weaker acidic nature of the sulfonic acid groups in S-CNF compared with the super-acid behaviour of the fluorinated sulfonic acid side chains in Nafion (Bayer et al. 2016a, Kreuer 2014, Eikerling et al. 2001). The activation energy for proton conduction in S-CNF is $0.26 \mathrm{eV}$, which is similar in all of the nanocellulose membranes. This is significantly higher than that of Nafion $(\sim 0.16 \mathrm{eV})$, indicating a higher degree of proton conduction via the vehicular mechanism rather than the Grotthuss mechanism. These measurements show that by tailoring the chemical structure of nanocellulose fibres, it is possible to increase the conductivity without compromising the membrane strength or stability. As such, S-CNF paper is highly suited as an ionomer membrane in real PEFCs. (b)

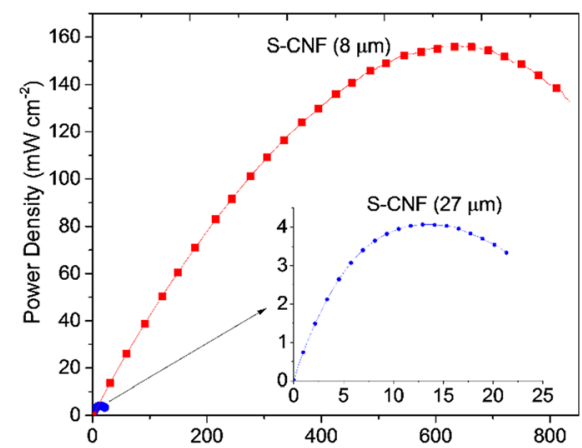

(d) Current Density $\left(\mathrm{mA} \mathrm{cm}^{-2}\right)$

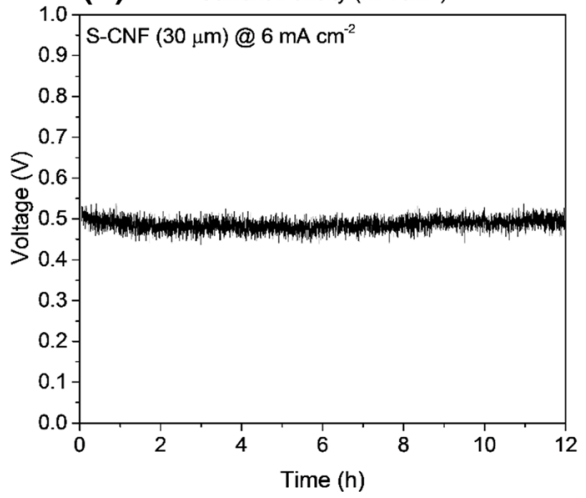

density for Nafion and the S-CNF-based fuel cells. d Constant load durability measurement of a $30 \mu \mathrm{m}$ thick S-CNF fuel cell

\section{Fuel cell performance}

The above experiments determined that S-CNF membranes could be a suitable replacement for Nafion in PEFCs. Therefore, MEAs were prepared using S-CNF membranes, and the performance was investigated at $80{ }^{\circ} \mathrm{C}$ and $95 \% \mathrm{RH}$. First, a $30 \mu \mathrm{m}$ thick S-CNF membrane was tested (Fig. 4a). The open circuit voltage $(\mathrm{OCV})$ is $0.90 \mathrm{~V}$, about $50 \mathrm{mV}$ lower compared to conventional Nafion fuel cells $(\sim 0.95 \mathrm{~V})$. However, the OCV of $0.9 \mathrm{~V}$ indicates that the S-CNF paper is electronically insulating, and that there is negligible hydrogen crossover. Unfortunately, the cell resistance is also very high (20.4 $\left.\Omega \mathrm{cm}^{-2}\right)$, as indicated by the steep gradient. The maximum power density was only $4.1 \mathrm{~mW} \mathrm{~cm}^{-2}$ at a current density of $13.5 \mathrm{~mA} \mathrm{~cm}{ }^{-2}$. Whilst this power density is 5 times higher than for an un-sulfonated CNF membrane of the same thickness (Bayer et al. 2016a), it is clearly much lower than for a typical Nafion-based PEMFC and not acceptable for real-world applications. This is 
attributed to the low proton conductivity of the membrane, leading to high cell resistance. The hydrogen crossover current measured in-situ ranges from 0.03 to $0.3 \mathrm{~mA} \mathrm{~cm}^{-2}$. This is much lower than that of Nafion ( $1 \mathrm{~mA} \mathrm{~cm}^{-2}$, Fig. 4c), which explains the high OCV. This is also many times lower than the DOE target for vehicular applications $\left(2 \mathrm{~mA} \mathrm{~cm}^{-2}\right.$ by 2020) (U.S. Department of Energy 2016), and is in excellent agreement with the low hydrogen permeability as measured ex-situ.

In order to take advantage of this low hydrogen crossover current and the high mechanical strength of nanocellulose paper, PEFCs with much thinner S-CNF membranes were prepared. This was expected to result in reduced membrane resistance and thus increased cell performance, without compromising fuel crossover. In previous work, we successfully reduced the cell resistance and improved the power density of PEFCs by spray-painting very thin Nafion, Aquivion, or graphene oxide (GO) ionomer membranes directly onto the electrocatalyst layer, creating electrodesupported MEAs rather than conventional membrane-supported MEAs (Bayer et al. 2016c; Bayer et al. 2017; Breitwieser et al. 2017). Here, an MEA was fabricated by spray deposition of a Pt/C electrocatalyst layer onto a gas diffusion layer (GDL), followed by spray deposition of an $8 \mu \mathrm{m}$-thick layer of S-CNF, and then spray deposition of a second electrocatalyst layer on top of this. Finally, a GDL was attached to the top surface to complete the MEA. This is a process analogous to additive manufacturing, or $3 \mathrm{D}$ printing.

The performance of the sprayed S-CNF paper fuel cell is shown in Fig. 4b. The maximum power density is $156 \mathrm{~mW} \mathrm{~cm}^{-2}$, which is $\sim 40$ times higher than that of the MEA with a thicker $30 \mu \mathrm{m}$ S-CNF membrane. The maximum current density is $0.8 \mathrm{~A}$ $\mathrm{cm}^{-2}$, which is 60 times higher than for the thicker MEA. This improvement is attributed directly to the decreased thickness, leading to much lower cell resistance, which was determined to be $0.3 \Omega \mathrm{cm}^{-2}$. Indeed, this cell resistance is only slightly higher than in a conventional $50 \mu \mathrm{m}$ thick Nafion MEA (i.e. 0.217 $\Omega \mathrm{cm}^{-2}$ ) (Bayer et al. 2016a).

However, a major issue at present is that the OCV of the spray-deposited S-CNF PEFC is just $0.45 \mathrm{~V}$. This is very low, and in line with the measured high hydrogen crossover current density $\left(449 \mathrm{~mA} \mathrm{~cm}^{-2}\right.$, Fig. 4c). This is attributed to hydrogen crossover either through cracks formed in the membrane during drying, or inhomogeneity in the carbon paper substrate resulting in pinholes (Bayer et al. 2016c; Breitwieser et al. 2017). Overcoming this issue is crucial in the development of thin-film nanocellulose PEFCs. This will be achieved in future work by optimization of the cell fabrication process (especially the spray deposition step) and by improving the integrity of the nanocellulose layer throughout the manufacturing process. Solving this issue and increasing the OCV to e.g. $>0.8 \mathrm{~V}$ would significantly improve the cell performance, even to the point where these new lowcost nanocellulose membranes become competitive with conventional Nafion. Another issue is that the performance dropped more quickly in the case of the thinner membrane, i.e. within the first 40 minutes of the durability test. We speculate that back-diffusion of water through the membrane results in swelling which affects thinner membranes more than the thicker membrane, increasing the rate of degradation. This is an issue that will be investigated further in the near future.

Whilst the power density is clearly lower than that of conventional Nafion MEAs (e.g. $\sim 712 \mathrm{~mW} \mathrm{~cm}^{-2}$ as fabricated in our group), we emphasize that this is a completely new class of ionomer. Sulfonated nanocellulose is many orders of magnitude cheaper than sulfonated fluoropolymers, is obtained from renewable sources, and it can be easily recycled. The performance is also comparable with other more wellestablished "low cost" PEFC technologies in the literature. For example, the performance is comparable to reports of other non-fluorinated hydrocarbon membrane materials, such as sulfonated polyimide (SPI), sulfonated poly ether ether ketone (SPEEK) (Zhang et al. 2013), or polybenzimidazole (PBI) (Kurdakova et al. 2010). Direct methanol fuel cells (DMFCs) are generally reported to have power densities of less than $150 \mathrm{~mW} \mathrm{~cm}{ }^{-2}$ (Brouzgou et al. 2012; Joghee et al. 2015), and even the best PEFCs fabricated with Pt-free electrocatalysts (e.g. Fe-N-C) have power densities of less than $400 \mathrm{~mW}$ $\mathrm{cm}^{-2}$ (Brouzgou et al. 2012; Serov et al. 2016).

The durability of a $30 \mu \mathrm{m}$ thick S-CNF PEFC was tested by operating a cell for 12 hours at a constant current density of $6 \mathrm{~mA} \mathrm{~cm}{ }^{-2}$ (Fig. 4d). The cell voltage was relatively stable for the duration of the test, with no significant degradation in performance. Whilst much longer durability measurements clearly 
need to be performed, this is an important first step in demonstrating the feasibility of nanocellulose fuel cells.

\section{Cost analysis}

Whilst the performance of nanocellulose is undoubtably lower than Nafion, this could be compensated for by the much lower cost. Nafion 212 membrane currently retails for $\sim 750 \mathrm{US} \$ \mathrm{~m}^{-2}$, and the DOE target for membrane cost is $20 \mathrm{US} \$ \mathrm{~m}^{-2}$ by 2020 . In the above sprayed S-CNF membrane, the overall material and chemical costs are $\sim 5.50 \mathrm{US} \$ \mathrm{~g}_{\mathrm{dry}}{ }^{-1}$, and the electrolyte is sprayed onto the electrode with a loading of $\sim 10 \mathrm{~g} \mathrm{~m}^{-2}$. This corresponds to a membrane cost of $\sim 50$ US $\$ \mathrm{~m}^{-2}$ for the $8 \mu \mathrm{m}$

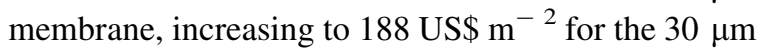
S-CNF membrane (Supplementary information, Figure S1). Even at such small production scale (several grams), the membrane cost is already approaching the DOE target. Economies of scale will reduce this cost even further. This technology thus paves the way for biodegradable, "pocket-money fuel cells", cheap enough even to be disposable, much like most portable primary or secondary batteries today.

\section{Conclusions}

Sulfonated cellulose nanofiber (S-CNF) paper was investigated as a replacement for Nafion in fuel cells for the first time. The tensile strength of the S-CNF paper was $49 \mathrm{MPa}$ (compared with $30 \mathrm{MPa}$ for Nafion), the hydrogen permeability was 2 orders of magnitude lower than Nafion, and the water uptake and swelling ratio were comparable to Nafion. The through-plane proton conductivity was $2 \times 10^{-3} \mathrm{~S}$ $\mathrm{cm}^{-1}$ at $120^{\circ} \mathrm{C}$, and the activation energy was $0.26 \mathrm{eV}$. S-CNF membranes were successfully introduced into "paper fuel cells" as a replacement for Nafion. The hydrogen crossover current in a fuel cell using a $30 \mu \mathrm{m}$ thick S-CNF membrane was two orders of magnitude lower than for Nafion, easily meeting DOE requirements. However, the power density was too small for practical applications. To take advantage of the excellent hydrogen barrier properties, a S-CNF fuel cell with a membrane thickness of $8 \mu \mathrm{m}$ was fabricated by spray deposition. The low resistance of the thin electrolyte compensated for the low proton conductivity, and the maximum power density reached $156 \mathrm{~mW} \mathrm{~cm}^{-2}$ at $80{ }^{\circ} \mathrm{C}$. This is competitive with other "low cost" fuel cell technologies reported in the literature, such as DMFCs. Cost analysis revealed that the sprayed S-CNF membranes cost just $50 \mathrm{US} \$ \mathrm{~m}^{-2}$, which is significantly less than Nafion, even at such small production scale. Considering the high mechanical strength, low hydrogen permeability, good stability, and extremely low cost of this new class of paper ionomer membrane, this work paves the way for low-cost fuel cells applications. If the proton conductivity can be further improved by altering the chemical structure of nanocellulose, and the integrity of the membrane can be improved, spray deposited nanocellulose paper fuel cells may even be able to compete directly with sulfonated fluoropolymers such as Nafion.

Acknowledgments The authors gratefully acknowledge the support of the Next-Generation Fuel Cell Research Center, Kyushu University; the QR Funding Program, Kyushu University, and the International Institute for Carbon Neutral Energy Research (WPI-I2CNER), sponsored by the World Premier International Research Center Initiative (WPI), MEXT, Japan. This research was also partially supported by the Center of Innovation Program from Japan Science and Technology Agency, JST; and a JSPS KAKENHI Grant-in-Aid for Young Scientists (B), Grant Number JP17K14087.

Author contributions T.B., B.V.C. and S.M.L. conceived this work. B.V.C. synthesized the materials. B.S. carried out XPS analysis. R.S. and S.F. carried out gas permeability measurements. T.B. carried out morphological analysis, tensile strength and water uptake measurements, Fenton's Test, FTIR and impedance measurements. T.B. fabricated and evaluated the fuel cells. T.B. performed the material cost analysis. T.B. and S.M.L. wrote the manuscript. K.S. contributed to the electrochemical discussions. All authors reviewed and commented on the manuscript and discussed the results before submission.

\section{Compliance with ethical standards}

Conflict of interest The authors declare no competing financial interests.

Open Access This article is licensed under a Creative Commons Attribution 4.0 International License, which permits use, sharing, adaptation, distribution and reproduction in any medium or format, as long as you give appropriate credit to the original author(s) and the source, provide a link to the Creative Commons licence, and indicate if changes were made. The images or other third party material in this article are included in the article's Creative Commons licence, unless indicated otherwise in a credit line to the material. If material is not 
included in the article's Creative Commons licence and your intended use is not permitted by statutory regulation or exceeds the permitted use, you will need to obtain permission directly from the copyright holder. To view a copy of this licence, visit http://creativecommons.org/licenses/by/4.0/.

\section{References}

Bayer T, Bishop SRSR, Nishihara M et al (2014) Characterization of a graphene oxide membrane fuel cell. J Power Sources 272:239-247. https://doi.org/10.1016/j.jpowsour. 2014.08.071

Bayer T, Cunning BV, Selyanchyn R et al (2016a) High temperature proton conduction in nanocellulose membranes: paper fuel cells. Chem Mater doi. https://doi.org/10.1021/ acs.chemmater.6b01990

Bayer T, Cunning BV, Selyanchyn R et al (2016b) Alkaline anion exchange membranes based on $\mathrm{KOH}$-treated multilayer graphene oxide. J Memb Sci 508:51-61. https://doi. org/10.1016/j.memsci.2016.02.017

Bayer T, Pham H-CC, Sasaki K et al (2016c) Spray deposition of Nafion membranes: electrode-supported fuel cells. J Power Sources 327:319-326. https://doi.org/10.1016/j.jpowsour. 2016.07.059

Bayer T, Selyanchyn R, Fujikawa S et al (2017) Spray-painted graphene oxide membrane fuel cells. J Memb Sci 541:347-357. https://doi.org/10.1016/j.memsci.2017.07. 012

Börjesson M, Westman G (2015) Chapter 7: Crystalline nanocellulose-preparation, modification, and properties. In: Ornaghi H Jr, Poletto M (eds) Cellulose-fundamental aspects and current trends, IntechOpen, ISBN: 9789535122296, 9535122290

Börjesson M, Sahlin K, Bernin D, Westman G (2018) Increased thermal stability of nanocellulose composites by functionalization of the sulfate groups on cellulose nanocrystals with azetidinium ions. J Appl Polym Sci 135:45963. https://doi.org/10.1002/app.45963

Breitwieser M, Bayer T, Büchler A et al (2017) A fully spraycoated fuel cell membrane electrode assembly using Aquivion ionomer with a graphene oxide/cerium oxide interlayer. J Power Sources 351:145-150. doi:https://doi. org/10.1016/j.jpowsour.2017.03.085

Brouzgou A, Song SQ, Tsiakaras P (2012) Low and non-platinum electrocatalysts for PEMFCs: current status, challenges and prospects. Appl Catal B Environ 127:371-388. https://doi.org/10.1016/j.apcatb.2012.08.031

Chen WJ, Martin CR (1994) Gas-transport properties of sulfonated polystyrenes. J Memb Sci 95:57-61. https://doi. org/10.1016/0376-7388(94)85028-3

Cooper K (2019) Progress toward accurate through-plane membrane resistance and conductivity measurement. ECS Trans 25:995-1007. https://doi.org/10.1149/1.3210653

Dufresne A (2013) Nanocellulose: a new ageless bionanomaterial. Mater Today 16:220-227. https://doi.org/10.1016/j. mattod.2013.06.004
Dufresne A, Thomas S, Pothan LA et al (eds) (2013) Biopolymer nanocomposites: processing, properties, and applications. Wiley, Hoboken

Eberle U, Müller B, von Helmolt R (2012) Fuel cell electric vehicles and hydrogen infrastructure: status 2012. Energy Environ Sci 5:8780-8798. doi:https://doi.org/10.1039/ c2ee22596d

Eikerling M, Kornyshev AA, Kuznetsov AM et al (2001) Mechanisms of proton conductance in polymer electrolyte membranes. J Phys Chem B 105:3646-3662. https://doi. org/10.1021/jp003182s

Fenton HJH (1894) LXXIII-Oxidation of tartaric acid in presence of iron. J Chem Soc Trans 65:899-910. https:// doi.org/10.1039/CT8946500899

Gadim TDO, Vilela C, Loureiro FJA et al (2016) Nafion ${ }^{\circledR}$ and nanocellulose: a partnership for greener polymer electrolyte membranes. Ind Crops Prod 93:212-218. https:// doi.org/10.1016/j.indcrop.2016.01.028

Gaspar D, Fernandes SN, de Oliveira AG et al (2014) Nanocrystalline cellulose applied simultaneously as the gate dielectric and the substrate in flexible field effect transistors. Nanotechnology 25:094008. https://doi.org/10. 1088/0957-4484/25/9/094008

Henriksson M, Berglund LA, Isaksson P et al (2008) Cellulose nanopaper structures of high toughness. Biomacromolecules 9:1579-1585. https://doi.org/10.1021/ bm800038n

Inaba M, Kinumoto T, Kiriake M et al (2006) Gas crossover and membrane degradation in polymer electrolyte fuel cells. Electrochim Acta 51:5746-5753. https://doi.org/10.1016/j. electacta.2006.03.008

Ismail MY, Patanen M, Sirviö JA et al (2019) Hybrid films of cellulose nanofibrils, chitosan and nanosilica-structural, thermal, optical, and mechanical properties. Carbohydr Polym 218:87-94. https://doi.org/10.1016/J.CARBPOL. 2019.04.065

Jiang G, Zhang J, Qiao J et al (2015) Bacterial nanocellulose/ Nafion composite membranes for low temperature polymer electrolyte fuel cells. J Power Sources 273:697-706. https://doi.org/10.1016/j.jpowsour.2014.09.145

Joghee P, Malik JN, Pylypenko S, O'Hayre R (2015) A review on direct methanol fuel cells - in the perspective of energy and sustainability. MRS Energy Sustain 2:E3. https://doi. org/10.1557/mre.2015.4

Kim J, Shim BS, Kim HS et al (2015) Review of nanocellulose for sustainable future materials. Int J Precis Eng Manuf Technlogy 2:197-213. https://doi.org/10.1007/s40684015-0024-9

Klingele M, Breitwieser M, Zengerle R, Thiele S (2015) Direct deposition of proton exchange membranes enabling high performance hydrogen fuel cells. J Mater Chem A 3:11239-11245. https://doi.org/10.1039/C5TA01341K

Kreuer KD (2014) Ion conducting membranes for fuel cells and other electrochemical devices. Chem Mater 26:361-380. https://doi.org/10.1021/cm402742u

Kurdakova V, Quartarone E, Mustarelli P et al (2010) PBI-based composite membranes for polymer fuel cells. J Power Sources 195:7765-7769. https://doi.org/10.1016/j. jpowsour.2009.09.064

Lee K-Y, Aitomäki Y, Berglund L et al (2014) On the use of nanocellulose as reinforcement in polymer matrix 
composites. Compos Sci Technol 105:15-27. https://doi. org/10.1016/j.compscitech.2014.08.032

Lin N, Dufresne A (2014) Nanocellulose in biomedicine: current status and future prospect. Eur Polym J 59:302-325. https://doi.org/10.1016/j.eurpolymj.2014.07.025

Marcinkoski J, Spendelow J, Wilson A et al (2015) Fuel Cell System Cost-2015. DOE Hydrog Fuel Cells Progr Rec Rec 15015

Momma K, Izumi F (2011) VESTA 3 for three-dimensional visualization of crystal, volumetric and morphology data. J Appl Crystallogr 44:1272-1276. https://doi.org/10.1107/ S0021889811038970

Nogi M, Iwamoto S, Nakagaito AN, Yano H (2009) Optically transparent nanofiber paper. Adv Mater 21:1595-1598. https://doi.org/10.1002/adma.200803174

Nogi M, Kim C, Sugahara T et al (2013) High thermal stability of optical transparency in cellulose nanofiber paper. Appl Phys Lett 102:181911. doi:https://doi.org/10.1063/1. 4804361

Peighambardoust SJ, Rowshanzamir S, Amjadi M (2010) Review of the proton exchange membranes for fuel cell applications. International Journal of Hydrogen Energy. Elsevier Ltd, pp 9349-9384

Rajalaxmi D, Jiang N, Leslie G, Ragauskas AJ (2010) Synthesis of novel water-soluble sulfonated cellulose. Carbohydr Res 345:284-290. doi:https://doi.org/10.1016/j.carres.2009.09. 037

RISI (2015) Global production of paper and board hit record levels in 2014. 2015 Annu. Rev. Glob. Pulp Pap. Stat

Rodella CB, Barrett DH, Moya SF et al (2015) Physical and chemical studies of tungsten carbide catalysts: effects of $\mathrm{Ni}$ promotion and sulphonated carbon. RSC Adv 5:23874-23885. https://doi.org/10.1039/c5ra03252k

Samms SR, Wasmus S, Savinell RF (1996) Thermal stability of Nafion ${ }^{\circledR}$ in simulated fuel cell environments. J Electrochem Soc 143:1498. https://doi.org/10.1149/1.1836669
Sasaki K, Li H-W, Hayashi A et al (eds) (2016) Hydrogen energy engineering - a Japanese perspective. Springer Japan, Tokyo

Serov A, Workman MJ, Artyushkova K et al (2016) Highly stable precious metal-free cathode catalyst for fuel cell application. J Power Sources 327:557-564. https://doi.org/ 10.1016/j.jpowsour.2016.07.087

Sethi J, Oksman K, Illikainen M, Sirviö JA (2018) Sonicationassisted surface modification method to expedite the water removal from cellulose nanofibers for use in nanopapers and paper making. Carbohydr Polym 197:92-99. https:// doi.org/10.1016/J.CARBPOL.2018.05.072

Sun Y, Ogden J, Delucchi M (2010) Societal lifetime cost of hydrogen fuel cell vehicles. Int $\mathrm{J}$ Hydrogen Energy 35:11932-11946. https://doi.org/10.1016/j.ijhydene.2010. 08.044

U.S. Department of Energy (2016) Fuel Cells. The Fuel Cell Technologies Office Multi-Year Research, Development, and Demonstration Plan, pp 1-58

Yee RSL, Rozendal R, Zhang K, Ladewig BP (2012) Cost effective cation exchange membranes: a review. Chem Eng Res Des 90:950-959. https://doi.org/10.1016/j.cherd.2011. 10.015

Zhang H, Zhang T, Wang J et al (2013) Enhanced proton conductivity of sulfonated poly(ether ether ketone) membrane embedded by dopamine-modified nanotubes for proton exchange membrane fuel cell. Fuel Cells 13:1155-1165. https://doi.org/10.1002/fuce.201300130

Publisher's Note Springer Nature remains neutral with regard to jurisdictional claims in published maps and institutional affiliations. 